\title{
Recommended intakes of vitamin D to optimise health, associated circulating 25-hydroxyvitamin D concentrations, and dosing regimens to treat deficiency: workshop report and overview of current literature
}

\author{
Michiel G. J. Balvers ${ }^{1,2}$, Elske M. Brouwer-Brolsma ${ }^{2}$, Silvia Endenburg ${ }^{1}$, Lisette C. P. G. M. de Groot ${ }^{2}$, \\ Frans J. Kok ${ }^{2}$ and Jacqueline Klein Gunnewiek ${ }^{1}$ \\ ${ }^{1}$ Clinical Chemistry and Haematology Laboratory, Gelderse Vallei Hospital, PO Box 9025, 6710 HN, Ede, the Netherlands \\ ${ }^{2}$ Division of Human Nutrition, Wageningen University, PO Box 8129, 6700 EV Wageningen, the Netherlands
}

(Received 1 October 2014 - Final revision received 10 October 2014 - Accepted 18 February 2015)

Journal of Nutritional Science (2015), vol. 4, e23, page 1 of 8

doi:10.1017/jns.2015.10

Abstract

Vitamin D is a fat-soluble hormone that traditionally has been linked to bone health. Recently, its involvement has been extended to other (extra-skeletal) disease areas, such as cancer, CVD, energy metabolism and autoimmune diseases. Vitamin D deficiency is a worldwide problem, and several recommendation-setting bodies have published guidelines for adequate vitamin D intake and status. However, recommendations from, for example, the Health Council of the Netherlands do not provide advice on how to treat vitamin D deficiency, a condition that is often encountered in the clinic. In addition, these recommendations provide guidelines for the maintenance of 'minimum levels', and do not advise on 'optimum levels' of vitamin D intake/status to further improve health. The NutriProfiel project, a collaboration between the Gelderse Vallei Hospital (Ede, the Netherlands) and the Division of Human Nutrition of Wageningen University (Wageningen, the Netherlands), was initiated to formulate a protocol for the treatment of vitamin deficiency and for the maintenance of optimal vitamin D status. To discuss the controversies around treatment of deficiency and optimal vitamin D status and intakes, a workshop meeting was organised with clinicians, scientists and dietitians. In addition, a literature review was conducted to collect recent information on optimal intake of vitamins, their optimal circulating concentrations, and effective dosing regimens to treat deficiency. This information has been translated into the NutriProfiel advice, which is outlined in this article.

Key words: Vitamin D: Workshop reports: Optimum intake: Deficiency

\section{Introduction}

Vitamin D is primarily obtained via exposure to UV light, which initiates vitamin D production in the skin. In addition, vitamin $\mathrm{D}$ can also be acquired through the diet. However, there are only a few natural food sources - fatty fish, meat, eggs, whole dairy products - and in the Netherlands only a limited number of foods are enriched with vitamin D, like fats, margarines and spreads ${ }^{(1,2)}$. Two types of vitamin D exist: vitamin $\mathrm{D}_{2}$, which is plant derived; and the animalderived vitamin $\mathrm{D}_{3}$. Most of the data presented in this paper focus on vitamin $\mathrm{D}_{3}$ (also known as cholecalciferol) because it is generally accepted that vitamin $\mathrm{D}_{3}$ is more effective than vitamin $\mathrm{D}_{2}^{(3)}$.

Traditionally, vitamin D has been linked to bone health, and most of the randomised clinical trials (RCT) have focused on bone mineralisation and fracture risk ${ }^{(1-3)}$. However, in recent years, observational studies have revealed an inverse association between vitamin $\mathrm{D}$ status and the risk of cancer, diabetes, cognitive decline and certain autoimmune diseases ${ }^{(1)}$. Despite the wealth of publications reporting on associations between vitamin $\mathrm{D}$ and these health outcomes, there is not yet consensus on optimal intakes of vitamin $\mathrm{D}$ and reference

Abbreviations: 25(OH)D, 25-hydroxyvitamin D; BMD, bone mineral density; IOM, Institute of Medicine; IU, international unit; RCT, randomised clinical trial.

* Corresponding author: Dr Jacqueline Klein Gunnewiek, fax +31 31843 4002, email kleingunnewiekj@zgv.nl 
concentrations of its metabolite, 25-hydroxyvitamin D (25 $(\mathrm{OH}) \mathrm{D})$, the widely accepted vitamin $\mathrm{D}$ status indicator ${ }^{(1)}$. This is partly due to the lack of RCT-based data for areas other than bone health ${ }^{(1,3)}$. In addition, the lack of guidelines to treat deficiency and the controversy around 'optimal' over 'minimum' vitamin D status has further fueled discussions in this field. Several recommendation-setting bodies have published vitamin D recommendations in recent years, such as the Institute of Medicine (IOM) ${ }^{(2)}$, the Scientific Advisory Council on Nutrition ${ }^{(4)}$ (update in preparation), the Health Council of the Netherlands ${ }^{(3)}$ and the Nordic Council of Ministers ${ }^{(5)}$. Most of these recommendations have set target $25(\mathrm{OH}) \mathrm{D}$ values of 30 or $50 \mathrm{nmol} / 1$ (summarised in Brouwer-Brolsma et al. $\left.{ }^{(1)}\right)$, which have been heavily debated by vitamin $\mathrm{D}$ experts who proposed higher target values ${ }^{(6-10)}$. These controversies have led to widespread diversity regarding the treatment of vitamin $\mathrm{D}$ deficiencies. At the same time, it has become clear that the incidence of vitamin $\mathrm{D}$ deficiency is rising in Northern Europe ${ }^{(11)}$, and increased hospitalisation rates for deficiency-related disorders, such as rickets in children, have been reported ${ }^{(12)}$. In its 2012 recommendations, the Health Council of the Netherlands summarised studies that explored the prevalence of vitamin D deficiency within the Dutch population, demonstrating that significant differences exist between different ethnic groups ${ }^{(3)}$. For instance, within pregnant women, the prevalence of vitamin $\mathrm{D}$ deficiency ranged from $8 \%$ among women with a Dutch background to $78 \%$ among women with a Turkish background. A similar picture emerged in adult men and women; vitamin $\mathrm{D}$ deficiency was found in approximately $10 \%$ of adults with a Dutch background, and in approximately $40 \%$ of adults with a Surinam background ${ }^{(3)}$. This indicates that vitamin D deficiencies are widely present in Northern European countries, and it is clear that current strategies need to be revised in order to improve vitamin D status.

In order to bridge this gap, the Clinical Chemistry and Haematology Laboratory of the Gelderse Vallei Hospital, together with the Division of Human Nutrition of Wageningen University, initiated NutriProfiel. NutriProfiel aims to provide advice to treat vitamin deficiency and subsequently maintain optimal vitamin status. In June 2013, a workshop meeting was organised to discuss the controversies around optimal vitamin D status and the treatment of deficiencies. The meeting was attended by participants with a variety of backgrounds, including dietitians, clinicians and nutrition scientists (see Appendix). In addition to the workshop meeting, a literature survey was performed to collect recent information on optimal vitamin D status and intakes, and the treatment of deficiency. Particular attention was given to recommendations of the $\mathrm{IOM}^{(2)}$ and the Health Council of the Netherlands ${ }^{(3)}$. Attention was also given to publications proposing different cut-off values and intakes related to deficiency and sufficiency for bone health. The present paper summarises the main conclusions from the workshop meeting and the literature survey. This paper combines strategies to treat vitamin $\mathrm{D}$ deficiency with a critical discussion of current recommendations, leading to the NutriProfiel recommendations. The vitamin $\mathrm{D}$ recommendations from the Health Council of the Netherlands served as the basis for this.

Optimal 25(OH)D concentrations and vitamin D intakes to maintain optimal levels are defined (section 2), followed by the introduction of a strategy to treat vitamin D deficiency (section 3). This document also discusses potential safety issues (section 4), and briefly explains differences between the NutriProfiel advice and the Netherlands Health Council advice (section 5). Finally, the recommendations are summarised (section 6).

\section{Optimal vitamin D intakes and 25-hydroxyvitamin D levels}

Vitamin D is traditionally linked to effects on bone health, for example, reducing fracture risk and increasing bone mineral density (BMD) ${ }^{(3)}$. Effects on other systems, such as the cardiovascular system, pancreas or immune system, are also reported in the literature, but this evidence is usually derived from observational studies, in which causality cannot be examined ${ }^{(1,3)}$. Most of the intervention studies have focused on bone health, and therefore this section is limited to this area ${ }^{(3)}$. In contrast to the Health Council of the Netherlands, that has advised on minimum levels, NutriProfiel aims to provide recommendations concerning optimal levels. In this section, we provide an overview of evidence to support recommendations for optimal levels of vitamin $\mathrm{D}$ status, and the intakes necessary to maintain this optimal status; treatment of deficiency will be discussed in section 3 .

\subsection{Data for $>65$-year-olds}

Several RCT have been performed, using diverse study populations, different doses of vitamin $\mathrm{D}$ with or without additional $\mathrm{Ca}$, different duration of supplementation and study outcome parameters. The studies have reported inconsistent conclusions concerning the relationship between vitamin $\mathrm{D}, 25$ $(\mathrm{OH}) \mathrm{D}$ concentrations and fracture risk, i.e. either no effect of vitamin $\mathrm{D}$, or a protective effect on fracture risk. Accordingly, meta-analyses have also reported inconsistent conclusions $^{(13-18)}$, even when relatively high doses of 800 international units $(\mathrm{IU}) / \mathrm{d}$ were given $(1 \mu \mathrm{g}$ vitamin $\mathrm{D}=40$ IU). These inconsistencies have been extensively discussed $^{(1,19)}$, which has led to several hypotheses that could explain the reported discrepancies. One hypothesis suggested that vitamin $\mathrm{D}$ was only effective in specific groups of subjects, for example, elderly living in nursing institutions. Another hypothesis was that only higher doses of vitamin D are effective, and not discriminating between different doses would mask a true effect. It was also suggested that the effect may depend on baseline and acquired circulating 25(OH)D concentrations and $\mathrm{Ca}$ intake. Finally, lower than expected compliance rates in the vitamin D-treated groups could have masked true effects of vitamin D.

A recent pooled analysis study by Bischoff-Ferrari et al. ${ }^{(15)}$ took several of these explanations into account, including subgroup analyses, relationship between fracture risk and baseline $25(\mathrm{OH}) \mathrm{D}$ concentrations, and actual intake of vitamin $\mathrm{D}$. No effect of vitamin $\mathrm{D}$ treatment on fracture risk was observed 
using intention-to-treat analysis or treatment-dose analysis. However, using actual-intake analysis, a significant relative risk (RR) reduction of $30 \%$ (RR 0.70; $95 \%$ CI 0.58, 0.86) for hip fracture risk and $14 \%$ (RR 0.86; $95 \%$ CI 0.76 , $0.96)$ for any non-vertebral fracture risk was observed when taking 792-2000 IU/d, whereas no effect was observed with lower vitamin $\mathrm{D}$ intakes ${ }^{(15)}$. Further analysis demonstrated that individuals having $25(\mathrm{OH}) \mathrm{D}$ concentrations of at least $61 \mathrm{nmol} / 1$ had a $37 \%$ (RR 0.63; $95 \%$ CI $0.46,0.87$ ) reduction of hip fracture risk and $31 \%$ (RR 0.69; $95 \%$ CI 0.57, $0.84)$ reduction of any non-vertebral fracture risk.

Individuals having baseline $25(\mathrm{OH}) \mathrm{D}$ concentrations of at least $43 \mathrm{nmol} / 1$ already had a significantly reduced risk for any non-vertebral fracture compared with $<30 \mathrm{nmol} / 1^{(15)}$. This suggests that $>50 \mathrm{nmol} / 1$ is an effective target concentration, whereas $>75 \mathrm{nmol} / 1$ is the optimal concentration. Additional subgroup analyses within the highest actual intake group revealed that the reduction in fracture risk was consistent across groups defined by age, type of dwelling, and additional $\mathrm{Ca}$ intake ${ }^{(15)}$. Two other reviews (from the same author) investigating dose-response relationships demonstrated that the anti-fracture efficacy of vitamin $\mathrm{D}$ was positively correlated with acquired $25(\mathrm{OH}) \mathrm{D}$ concentrations, showing beneficial effects from about $50 \mathrm{nmol} / 1$ and optimal fracture reduction when concentrations of about 75-100 $\mathrm{nmol} / 1$ were reached ${ }^{(16,20)}$. This dose-dependent effect was also reported in subgroup analyses in other meta-analyses, and the IOM has acknowledged that those individuals who reach at least $75 \mathrm{nmol} / 1$ are likely to have a reduced fracture risk $^{(1)}$. In conclusion, it is clear that only higher vitamin D intakes (about $20 \mu \mathrm{g} / \mathrm{d}$ ) are effective in reducing fracture risk in those individuals reaching $25(\mathrm{OH}) \mathrm{D}$ concentrations of $>75 \mathrm{nmol} / 1$, and it may be that this finding was missed in some previous meta-analyses due to methodological differences compared with the meta-analyses outlined above (for example, not taking actual vitamin $\mathrm{D}$ intake into account, or not discriminating between doses of vitamin D). It must be noted that all studies that used $20 \mu \mathrm{g} / \mathrm{d}$ of vitamin $\mathrm{D}$ also provided additional $\mathrm{Ca}$ to the participants.

Published dose-response studies have shown that the 25(OH)D concentration rises with approximately $1 \mathrm{nmol} / 1$ for each $1 \mu \mathrm{g} / \mathrm{d}$ of vitamin $\mathrm{D}$ given ${ }^{(21,22)}$. Thus, when baseline $25(\mathrm{OH}) \mathrm{D}$ concentrations are low, levels of $75-100 \mathrm{nmol} / 1$ are unlikely to be reached with $800 \mathrm{IU} / \mathrm{d}$ in the short term, which may explain the lack of anti-fracture efficiency in some studies that supplemented $800 \mathrm{IU} / \mathrm{d}$ of vitamin D in (severely) deficient patients (discussed in Bischoff-Ferrari et al. ${ }^{(20)}$ ). Although positive effects are observed at $>50 \mathrm{nmol} / \mathrm{l}$, we propose to define the optimal range at $75-100 \mathrm{nmol} / \mathrm{l}$; this will allow some buffering capacity so that $25(\mathrm{OH}) \mathrm{D}$ levels will not drop below $50 \mathrm{nmol} / 1$ in the case of seasonal influences or temporary malabsorption problems. In the case of a severely deficient patient, we therefore propose to divide the treatment procedure into two stages: first treating the deficiency and subsequently confirming whether the optimum range has been reached, after which the maintenance dose will be prescribed; this will be described in more detail in section 3. During the winter period, intakes of $20 \mu \mathrm{g} / \mathrm{d}$ vitamin D will result in about $50 \%$ of the elderly population maintaining $25(\mathrm{OH}) \mathrm{D}$ concentrations of $>80 \mathrm{nmol} / 1$ during winter and $90-95 \%$ of the population maintaining $>50 \mathrm{nmol} / 1$ during winter ${ }^{(23,24)}$. Intakes of $30-40 \mu \mathrm{g} / \mathrm{d}$ would be required to ensure that $97.5 \%$ of the population would maintain $>80$ $\mathrm{nmol} / 125(\mathrm{OH}) \mathrm{D}^{(24-26)}$.

When reviewing the available literature in 2010, eight out of ten members of the International Osteoporosis Foundation Working Group concluded that $75 \mathrm{nmol} / 1$ should be the target value for $25(\mathrm{OH}) \mathrm{D}$, and two members concluded that the target should be between 50 and $75 \mathrm{nmol} / \mathrm{l}^{(26)}$. These target concentrations are clearly higher than recommended by the IOM or DACH (German, Austria and Switzerland recommendation) $(50 \mathrm{nmol} / \mathrm{l})$ or the Netherlands Health Council (30 or $50 \mathrm{nmol} / 1$, depending on age) $)^{(1)}$, which resulted obviously in different conclusions when reviewing the data.

We conclude that it has been sufficiently shown that $\geq 20$ $\mu \mathrm{g} / \mathrm{d}(800 \mathrm{IU} / \mathrm{d})$ is effective in reducing fracture risk in $\geq 65$-year-old subjects. Therefore, we recommend that individuals aged $>65$ years consume $20 \mu \mathrm{g} / \mathrm{d}(800 \mathrm{IU} / \mathrm{d})$ of vitamin D. In addition, we conclude that $75-100 \mathrm{nmol} / 1$ is the optimal $25(\mathrm{OH}) \mathrm{D}$ range to ensure an optimal anti-fracture effect which allows some buffering capacity to maintain levels above the effective concentration of $50 \mathrm{nmol} / \mathrm{l}$. The dose of $20 \mu \mathrm{g} / \mathrm{d}$ will ensure these levels for $50 \%$ of the population, whereas $90-95 \%$ of the population will maintain the effective range of $>50 \mathrm{nmol} / 125(\mathrm{OH}) \mathrm{D}$. The $50 \mathrm{nmol} / 1$ cut-off is also regarded effective by the Netherlands Health Council.

The acquired circulating $25(\mathrm{OH}) \mathrm{D}$ level is positively related to the anti-fracture effect of vitamin $\mathrm{D}$. In cases of low baseline $25(\mathrm{OH}) \mathrm{D}$ levels, the $20 \mu \mathrm{g} / \mathrm{d}$ vitamin D supplementation dose appears to be insufficient in reaching the target $25(\mathrm{OH}) \mathrm{D}$ level of $>50 \mathrm{nmol} / \mathrm{l}$ within a short time. Therefore, we propose that circulating $25(\mathrm{OH}) \mathrm{D}$ levels should be measured to identify and treat any pre-existing deficiency before switching to the $20 \mu \mathrm{g} / \mathrm{d}$ maintenance dose that is known to reduce the risk of fractures. Subsequently, additional $25(\mathrm{OH})$ $\mathrm{D}$ analyses after 3 and 9 months of supplementation will determine whether the optimal range of $75-100 \mathrm{nmol} / \mathrm{l}$, or at least the effective range of $>50 \mathrm{nmol} / 1$, is reached. Treatment strategies for vitamin D deficiency will be discussed in section 3 .

\subsection{Data for 0- to 64-year-olds}

There is sufficient evidence that vitamin $\mathrm{D}$ supplementation prevents rickets in young children up to 4 years old, but there are considerably fewer data available to determine optimal intakes and target concentrations for individuals aged 5-65 years ${ }^{(3)}$. The Netherlands Health Council recommends an intake of $10 \mu \mathrm{g} / \mathrm{d}(400 \mathrm{IU} / \mathrm{d})$ to ensure $25(\mathrm{OH}) \mathrm{D}$ concentrations of $30 \mathrm{nmol} / 1$, which is sufficient to prevent rickets in children up to 4 years old. This is well below the upper intake level of 1000-3000 IU/d as defined by the IOM for children ${ }^{(2,3)}$. Reference values for $25(\mathrm{OH}) \mathrm{D}$ and vitamin $\mathrm{D}$ intake for older children and adults are based on this observation, although effectiveness has not been studied extensively ${ }^{\left({ }^{(3)}\right.}$. In addition, the relationships between vitamin $\mathrm{D}$ and BMD in 
children and adults are not clear ${ }^{(3)}$, but observational studies have suggested that an association exists between 25(OH)D concentrations and BMD. Based on this relationship with $\mathrm{BMD}$, and the potential protective effect on colorectal cancer, it has been proposed by others that target $25(\mathrm{OH}) \mathrm{D}$ levels of $50-75 \mathrm{nmol} / 1$ are justified for this group ${ }^{(20)}$. These levels will be maintained for $50 \%$ of the population with $10 \mu \mathrm{g} / \mathrm{d}$ vitamin D intake, and $20-25 \mu \mathrm{g} / \mathrm{d}$ would be required to ensure that $97.5 \%$ of the general population maintains $>50$ $\mathrm{nmol} / \mathrm{l}^{(3,24-26)}$. The 10 to $20 \mu \mathrm{g} / \mathrm{d}$ is in line with the Netherlands Health Council $(10 \mu \mathrm{g} / \mathrm{d})$ and the $\mathrm{DACH}$ guidelines $(20 \mu \mathrm{g} / \mathrm{d})$ and well below the IOM upper intake levels of $100 \mu \mathrm{g} / \mathrm{d}$ for adults (see below) ${ }^{(1)}$.

No specific recommendations have been established for pregnant and lactating women, because there are no indications that these groups have a specific higher requirement for vitamin $\mathrm{D}^{(3)}$. Furthermore, there are not enough data available to support different vitamin $\mathrm{D}$ requirements for individuals with a dark skin type. However, due to the less efficient endogenous vitamin D synthesis, supplementation is recommended for individuals with a dark skin type ${ }^{(3)}$.

In agreement with other recommendations for children aged $0-4$ years, we propose $10 \mu \mathrm{g} / \mathrm{d}(400 \mathrm{IU})$ and reference values of $30 \mathrm{nmol} / 125(\mathrm{OH}) \mathrm{D}$.

For ages 5-64 years, we conclude that there is a lack of solid evidence that supports well-defined recommendations for vitamin D supplementation. Although BMD is an indirect measure of bone health, we consider it to be beneficial to optimise BMD throughout life. Although solid data from intervention studies are lacking, observational studies have reported a positive association between $25(\mathrm{OH}) \mathrm{D}$ level and BMD, suggesting an optimal concentration range of $50-75 \mathrm{nmol} / \mathrm{l}$. We therefore assume that $50-75 \mathrm{nmol} / 1$ is the optimal range for ages 5-64 years. At least $10 \mu \mathrm{g} / \mathrm{d}$ (400 $\mathrm{IU} / \mathrm{d})$ is required to ensure $25(\mathrm{OH}) \mathrm{D}$ concentrations of $>50 \mathrm{nmol} / 1$ for $50 \%$ of the population, and preferably 20 $\mu \mathrm{g} / \mathrm{d}(800 \mathrm{IU} / \mathrm{d})$ is recommended for this $25(\mathrm{OH}) \mathrm{D}$ level for $97.5 \%$ of the population. No special requirements are made for pregnant or lactating women, or individuals with a dark skin type. Similar to ages $>65$ years, we propose to measure $25(\mathrm{OH}) \mathrm{D}$ levels at baseline to identify and treat any deficiency, and to confirm after 3 and 9 months that optimal levels are reached.

\section{Regimens for treating vitamin D deficiency and maintaining optimal levels}

There are indications that vitamin $\mathrm{D}$ intakes that are described in the current literature to maintain adequate $25(\mathrm{OH}) \mathrm{D}$ levels will not be sufficient to correct a deficient state. Therefore, a main aim of NutriProfiel is to provide a recommendation to treat vitamin deficiency before maintaining optimal vitamin status. Although many protocols for the treatment of deficiency are being used in healthcare practice, the evidencebased foundation of these protocols is often lacking. This section describes the relationship between vitamin $\mathrm{D}$ intake and status, introduces a loading protocol to treat deficiency in adults, and provides recommendations for the maintenance dose regimen once the optimal 25(OH)D levels are reached. Also the influence of UV exposure on vitamin D status is discussed.

\subsection{Maintaining and correcting vitamin D status}

Considerable efforts have been made to investigate the effect of different vitamin $\mathrm{D}$ doses on circulating $25(\mathrm{OH}) \mathrm{D}$ concentrations. To date, the published dose-response studies have revealed that $1 \mu \mathrm{g} / \mathrm{d}$ of vitamin $\mathrm{D}$ is required for each $1 \mathrm{nmol} / 1$ increase of $25(\mathrm{OH}) \mathrm{D}^{(6,21,22)}$. Cashman et al. calculated that about $10 \mu \mathrm{g} / \mathrm{d}$ of vitamin $\mathrm{D}$ will result in only 50 $\%$ of the population reaching $25(\mathrm{OH}) \mathrm{D}$ concentrations of $>50 \mathrm{nmol} / 1^{(23-25)}$. In fact, doses of at least $20 \mu \mathrm{g} / \mathrm{d}$ would be needed to ensure that $50 \%$ of the population would maintain $>80 \mathrm{nmol} / 125(\mathrm{OH}) \mathrm{D}$, and $97.5 \%$ of the adult population would maintain $25(\mathrm{OH}) \mathrm{D}$ levels of $>50 \mathrm{nmol} / 1$ during winter (following summer-time levels of about $60-70 \mathrm{nmol} / \mathrm{l})$. This intake level, which is two times higher than the Health Council recommends for individuals aged $<70$ years, is considered to be insufficient to raise $25(\mathrm{OH})$ D levels above $75 \mathrm{nmol} / 1$ in most of the individuals, underlining the need for loading protocols before maintenance dosing ${ }^{(25,27,28)}$. It has also been described that elderly respond less to supplementation due to lower baseline levels ${ }^{(28)}$. All together, this provides strong arguments to start with a loading dose to ensure that optimal $25(\mathrm{OH}) \mathrm{D}$ levels are quickly reached before switching to the maintenance dose.

The usefulness of loading protocols has been discussed before ${ }^{(28)}$. Van Groningen et al. ${ }^{(27)}$ undertook a dose-escalation study using subjects with a wide variety in age (18-88 years old), baseline $25(\mathrm{OH}) \mathrm{D}$ levels (range: $<10$ to $47 \mathrm{nmol} / \mathrm{l}$ ) and body weight to determine an optimal loading-dose protocol. By measuring $25(\mathrm{OH}) \mathrm{D}$ before and after supplementation using different loading regimens, they were able to demonstrate that baseline levels and dose per kg body weight are the most important factors influencing the dose-response curve. In contrast, age, sex, BMI, body length or season did not significantly affect the rise in circulating $25(\mathrm{OH}) \mathrm{D}$ levels ${ }^{(27)}$. A simplified relationship was extracted, being: $\Delta 25$ $(\mathrm{OH}) \mathrm{D}=0.025 \times$ dose per $\mathrm{kg}$ body weight (in IU). A similar finding was presented by Drincic et al. ${ }^{(29)}$, who showed that the response to oral vitamin $\mathrm{D}$ depended on body size. In addition, they recommend that the loading dose should be given in portions of $25000 \mathrm{IU}$ per week, and that the formula is not valid for individuals $<18$ years of age, having a body weight $>125 \mathrm{~kg}$, or having a BMI of $>40 \mathrm{~kg} / \mathrm{m}^{2}$. To ensure that target $25(\mathrm{OH}) \mathrm{D}$ levels are reached, measurements at 3 and 9 months after the start of supplementation should be performed.

For deficiency treatment in children $<18$ years old, no specific loading regimens have been reported. Therefore, we propose to dose the generally accepted $1 \mu \mathrm{g} / \mathrm{d}$ for any $1 \mathrm{nmol} / \mathrm{l}$ $25(\mathrm{OH}) \mathrm{D}$ increase that is required to reach optimal levels with the understanding that the accepted upper daily intake levels that have been set for children (see Table 1) should never be exceeded. To ensure that target $25(\mathrm{OH}) \mathrm{D}$ levels 
Table 1. Summary of NutriProfiel recommendations for circulating 25-hydroxyvitamin $D(25(\mathrm{OH}) \mathrm{D})$ concentrations and vitamin $\mathrm{D}$ intake, split per age group

\begin{tabular}{|c|c|c|c|c|c|c|}
\hline \multirow[b]{2}{*}{ Age group } & \multicolumn{3}{|c|}{ Circulating 25(OH)D (nmol/l) } & \multicolumn{2}{|c|}{ Vitamin $\mathrm{D}_{3}$ intake } & \multirow[b]{2}{*}{ Upper daily intake $\left(\mathrm{IU} / \mathrm{d}^{*}\right)$} \\
\hline & Deficiency & Sufficiency & Optimal & $\mu \mathrm{g} / \mathrm{d}$ & $\mathrm{IU} / \mathrm{d}^{*}$ & \\
\hline 0-6 months & $<20$ & $20-30$ & $30-50$ & 10 & 400 & 1000 \\
\hline $6-12$ months & $<20$ & $20-30$ & $30-50$ & 10 & 400 & 1500 \\
\hline $1-4$ years & $<20$ & $20-30$ & $30-50$ & 10 & 400 & $2500 \dagger$ \\
\hline $5-8$ years & $<30$ & $30-50$ & $50-75$ & $10-20$ & $400-800$ & 3000 \\
\hline $8-64$ years & $<30$ & $30-50$ & $50-75$ & $10-20$ & $400-800$ & 4000 \\
\hline > 65 years & $<50$ & $50-75$ & $75-100$ & 20 & 800 & 4000 \\
\hline
\end{tabular}

* $1 \mu \mathrm{g}$ vitamin $\mathrm{D}=40 \mathrm{IU}$.

† Upper daily intake for 4-year-olds is $3000 \mathrm{IU}$.

are reached, measurements at 3 and 9 months after the start of supplementation should be performed. It is good to note that this advice is different from what is described in the Netherlands 'Farmacotherapeutisch Kompas'.

It is concluded that vitamin D loading is needed to ensure that target $25(\mathrm{OH}) \mathrm{D}$ levels are quickly reached before following the recommended maintenance dose. First, serum $25(\mathrm{OH}) \mathrm{D}$ concentration should be determined in all subjects. When subjects are already in the optimal range, no loading is required and subjects can directly follow the recommended dose (see sections 2 and 3.2). When a subject is deficient, the Van Groningen protocol ${ }^{(27)}$ is suitable to resolve this for all adults $>18$ years old. For children $<18$ years old, deficiency can be treated by loading with $1 \mu \mathrm{g} / \mathrm{d}$ for any desired $1 \mathrm{nmol} / 1$ increase in 25(OH)D. As already mentioned above, circulating 25(OH)D levels should be analysed after 3 and 9 months to verify that optimal $25(\mathrm{OH}) \mathrm{D}$ concentrations are reached.

\subsection{Administration of maintenance dose}

Once the optimal $25(\mathrm{OH}) \mathrm{D}$ levels are reached, the maintenance vitamin $\mathrm{D}$ dose can be supplemented on a daily, weekly, monthly or yearly basis. The half-life of vitamin $\mathrm{D}_{3}$ varies between 3 and 6 weeks $^{(30)}$ so it can be expected that a yearly bolus supplementation will not ensure stable circulating $25(\mathrm{OH}) \mathrm{D}$ levels throughout the year. In fact, a yearly bolus regimen is not recommended in the literature due to lack of efficacy and suboptimal gastrointestinal absorption. As a rule of thumb, a drug should be administered at least once during its half-life. This means that protocols that describe supplementation once every 3 or 4 months are clearly inadequate. Based on the pharmacokinetic profile, daily or weekly administration of vitamin D is likely to result in the most stable $25(\mathrm{OH}) \mathrm{D}$ concentrations, but there are no data available that support a choice between the two options based on clinical outcomes. For convenience, we recommend to ensure vitamin $\mathrm{D}$ intake on a daily basis. If this would not be feasible for any reason, then weekly administration is a suitable second choice.

It is recommended to administer the optimal vitamin D dose (see section 2) preferably on a daily basis, and to consider weekly administration when daily administration is not feasible.

\subsection{Interaction with UV exposure/endogenous vitamin D synthesis and use of supplements}

Exposure to UV light drives the endogenous synthesis of vitamin $\mathrm{D}$ in the skin, and this contributes to the vitamin D status. It is, however, very difficult to make precise estimations of the amounts that are synthesised at the population level due to the fact that skin synthesis depends on a number of factors that are highly variable between individuals, such as skin surface area exposed to sun, duration of sun exposure, use of sun creams, time of day/year and efficiency of the skin to synthesise vitamin $\mathrm{D}^{(3)}$. Precise data are lacking for the Netherlands, but the variation in vitamin $\mathrm{D}$ synthesis is estimated to range between $>10 \mu \mathrm{g} / \mathrm{d}$ in summer to virtually no endogenous synthesis during winter, and depends on many factors. The Health Council of the Netherlands acknowledges the lack of solid individual data to make reliable quantifications of the contribution of UV exposure to the vitamin D status, but recommended that individuals with a light skin type who get sufficient exposure to sun light produce enough endogenous vitamin $\mathrm{D}$ to meet the requirements and are therefore not advised to use vitamin D supplements. Sufficient sun exposure is defined as spending 15-30 min outdoor between 11.00 and 15.00 hours from March to November, with head and hand skin areas exposed to the sun; based on indirect calculations, this amount of sun exposure is expected to be sufficient to synthesise on average $6-7 \mu \mathrm{g} / \mathrm{d}$ throughout the year. The Health Council has proposed that individuals with a dark skin type, or those who do not get sufficient exposure to UV light, should use vitamin D supplements in order to meet the requirements ${ }^{(3)}$. In addition, all women between 50 and 70 years of age are advised to take a $10 \mu \mathrm{g} / \mathrm{d}$ supplement, and all adults over 70 years of age are advised to take a $20 \mu \mathrm{g} /$ $\mathrm{d}$ supplement to ensure that the vitamin $\mathrm{D}$ requirements are met ${ }^{(3)}$.

We conclude that the inter-individual and seasonal variation in sun exposure and hence endogenous vitamin D synthesis is quite large. The recommended vitamin $\mathrm{D}$ intake should be sufficient throughout the whole year to maintain optimal levels. The need to use supplements depends on skin type and UV exposure. Individuals with a dark skin type, or individuals that do not get sufficient amounts of UV light exposure, should use supplements to meet the vitamin $\mathrm{D}$ requirements and maintain their vitamin $\mathrm{D}$ levels. In addition, women over 50 years are advised to use $10 \mu \mathrm{g} / \mathrm{d}$ using a supplement, 
and all adults $>70$ years are advised to use a $20 \mu \mathrm{g} / \mathrm{d}$ supplement.

\section{Safety of vitamin D supplementation}

\subsection{Toxicology of vitamin D}

Safety of vitamin $\mathrm{D}$ has received much attention in the past, but there are still many uncertainties. The primary consequence of vitamin D intoxication is the development of hypercalcaemia, which could lead to adverse effects such as vomiting, pain, fever, anorexia and weight loss. Information about vitamin $\mathrm{D}$ intoxication is limited to anecdotal evidence, with extremely high intakes of at least $1250 \mu \mathrm{g} / \mathrm{d}$ or extremely high UV exposure causing classical signs of toxicity ${ }^{(31,32)}$. So far, most controlled experiments supplementing about 10 to about $1000 \mu \mathrm{g} / \mathrm{d}$ of vitamin D (including additional Ca in some cases) did not report any adverse effects or hypercalcae$\mathrm{mia}^{(28,31,32)}$. There seems to be consensus that a prolonged daily intake of $250 \mu \mathrm{g} / \mathrm{d}(10000 \mathrm{IU} / \mathrm{d})$ does not cause adverse effects $^{(1,3)}$. The IOM has converted this with a safety factor of 2.5 into $100 \mu \mathrm{g} / \mathrm{d}(4000 \mathrm{IU} / \mathrm{d})$ as a safe upper limit of intake for adults, and defined 1000-3000 IU for children up to 8 years $^{(1,2)}$. Circulating 25(OH)D levels of up to $220 \mathrm{nmol} / 1$ are considered to be safe because these levels correspond with prolonged intake of $250 \mu \mathrm{g} / \mathrm{d}$, for which no change in circulating $\mathrm{Ca}$ levels were observed ${ }^{(28,32)}$. In addition, 25 $(\mathrm{OH}) \mathrm{D}$ concentrations up to $140 \mathrm{nmol} / 1$ were not associated with an increased all-cause mortality risk, whereas concentrations $<75 \mathrm{nmol} / 1$ showed an increased risk for all-cause mortality $^{(33)}$. Another recent meta-analysis demonstrated that serum 25(OH)D concentrations below $75 \mathrm{nmol} / 1$ were associated with higher all-cause mortality compared with concentrations higher than $75 \mathrm{nmol} / \mathrm{l}^{(34)}$. These studies suggest that a J-shaped relationship exists between circulating 25(OH)D concentrations and all-cause mortality. This finding supports the previous notion that $25(\mathrm{OH}) \mathrm{D}$ concentrations up to $220 \mathrm{nmol} / \mathrm{l}$ are safe, and that concentrations higher than 75 $\mathrm{nmol} / \mathrm{l}$ may result in beneficial health effects.

High vitamin $\mathrm{D}$ intake combined with high Ca intake may increase CVD risk or the formation of renal stones, which could be explained by a high use of self-selected supplements ${ }^{(1,32)}$, underlining the need for careful well-founded dietary advice. In conclusion, the IOM considers vitamin D intakes of up to $100 \mu \mathrm{g} / \mathrm{d}$ safe for the general population. No specific guidelines for pregnant or lactating women, infants, children, elderly or specific diseases were found, except some specific warnings for individuals with high $\mathrm{Ca}$ intake (see below).

Following the IOM's recommendations, vitamin D supplementation up to $100 \mu \mathrm{g} / \mathrm{d}(=4000 \mathrm{IU} / \mathrm{d})$ for adults, and serum 25(OH)D levels up to $220 \mathrm{nmol} / \mathrm{l}$, can be considered safe. Different upper intake levels, as set by the IOM, should be applied for children, being $25 \mu \mathrm{g} / \mathrm{d}$ (1000 IU/d) for 0-6 months, $37.5 \mu \mathrm{g} / \mathrm{d}(1500 \mathrm{IU} / \mathrm{d})$ for 6-12 months, $65.5 \mu \mathrm{g} /$ d (2500 IU/d) for $1-3$ years, and $75 \mu \mathrm{g} / \mathrm{d}(3000 \mathrm{IU} / \mathrm{d})$ for 4-8 years of age. Caution should be taken when $\mathrm{Ca}$ is supplemented in addition to vitamin D.

\subsection{Effect of calcium in combination with vitamin $D$}

$\mathrm{Ca}$ is important for bone health, and the effect and safety of additional $\mathrm{Ca}$ intake on bone health in the context of vitamin $\mathrm{D}$ supplementation is heavily debated. As indicated above, a pooled analysis demonstrated that only the highest vitamin D supplementation doses would reduce fracture risk independent of $\mathrm{Ca}$ intake, which is supported by findings that with sufficient $\mathrm{Ca}$ and vitamin $\mathrm{D}$ intake, a higher $\mathrm{Ca}$ intake does not improve bone health ${ }^{(30)}$. A meta-analysis revealed that high Ca intakes (about 500-1000 mg/d from supplements) may be related to cardiovascular events and kidney stones in subjects that already had about $800 \mathrm{mg} / \mathrm{d} \mathrm{Ca}$ intake ${ }^{(35)}$; high $\mathrm{Ca}$ intakes from supplements should therefore be avoided. Recommendations for adequate $\mathrm{Ca}$ intake in the Netherlands vary between 1000 and $1200 \mathrm{mg}$ per $\mathrm{d}^{(36)}$. The exact interaction between (supplemental) Ca, vitamin D and adverse health effects is still a matter of ongoing research. To the best of our knowledge, we have not found any data that suggest that the proposed optimum intakes of 20-25 $\mu \mathrm{g} / \mathrm{d}$ vitamin $\mathrm{D}$, in combination with a total $\mathrm{Ca}$ intake of $1000-1200 \mathrm{mg} / \mathrm{d}$, will result in adverse health effects. There are indications that individuals with a Turkish, Moroccan or Surinamese background have inadequate $\mathrm{Ca}$ intakes ${ }^{(36)}$; in these cases it may be useful to administer supplemental $\mathrm{Ca}$ although care must be taken to avoid hypercalcaemia. It must be noted that the effectiveness of such a 'personalised' strategy (for example, only supplementing $\mathrm{Ca}$ in at-risk groups) remains to be demonstrated.

We conclude that supplemental Ca intake has no beneficial effect on fracture risk when vitamin D intake is already sufficient. Intakes of $\mathrm{Ca}$ in excess of dietary recommendations might cause cardiovascular events or kidney problems. Therefore, we do not recommend $\mathrm{Ca}$ supplementation in addition to vitamin $\mathrm{D}$ when $\mathrm{Ca}$ intake is already between 1000 and $1200 \mathrm{mg} / \mathrm{d}$. Additional Ca can be considered when dietary $\mathrm{Ca}$ intake is inadequate. Milk, dairy products and cheese are foods that contain $\mathrm{Ca}$ and could be used to increase $\mathrm{Ca}$ intake.

\section{Differences compared with the Netherlands Health Council advice on vitamin D}

The NutriProfiel recommendations for intakes of vitamin D and target concentrations of $25(\mathrm{OH}) \mathrm{D}$ are different from recommendations made in 2012 by the Netherlands Health Council $^{(3)}$. Major discrepancies are the difference between minimum and optimum vitamin $\mathrm{D}$ intakes, and the inclusion of a deficiency treatment strategy in the NutriProfiel advice, which will be outlined below.

The Health Council made recommendations to ensure 'minimum' levels of $25(\mathrm{OH}) \mathrm{D}$ to prevent bone disease, for which they have carefully weighed the available data before formulating their recommendations. The purpose of NutriProfiel is to provide a comprehensive approach of vitamin D status testing, treatment of deficiency, and maintenance of optimal $25(\mathrm{OH}) \mathrm{D}$ levels, and for this purpose we have examined the available scientific literature. There is a 
considerable amount of data from RCT that does support the significance of $>50 \mathrm{nmol} / 1$, and this is discussed elsewhere $^{(6-8,15,16,20)}$. In addition, meta-analyses of RCT investigating bone health have supported the notion that there are additional health benefits when concentrations of $>75 \mathrm{nmol} / 1$ are reached in elderly ${ }^{(15,16,20)}$. Since safety does not seem to be an issue, and levels of $75 \mathrm{nmol} / 1$ are encountered on a routine basis in the Netherlands ${ }^{(6)}$, we conclude that there is sufficient evidence to define $>50 \mathrm{nmol} / 1$ and $>75 \mathrm{nmol} / 125(\mathrm{OH}) \mathrm{D}$ as the optimum concentrations for 5-64 and $>65$ years of age, respectively, for which there are no safety concerns. Regarding the vitamin D intake for 5-64 years old, $10 \mu \mathrm{g} / \mathrm{d}$ and preferably $20 \mu \mathrm{g} / \mathrm{d}$ are based on dose-finding studies that revealed that this intake is sufficient to maintain 25 $(\mathrm{OH}) \mathrm{D}$ levels at $>50 \mathrm{nmol} / 1$ in about $97.5 \%$ of the adult population. For $>65$ years of age, the $20 \mu \mathrm{g} / \mathrm{d}(1000 \mathrm{IU} / \mathrm{d})$ dose is chosen based on meta-analysis that revealed that $>20 \mu \mathrm{g} / \mathrm{d}(800 \mathrm{IU} / \mathrm{d})$ was effective in preventing hip fractures. It is good to note that the NutriProfiel recommendations are largely in line with DACH guidelines, and that the recommended intakes are well below internationally accepted upper intake levels.

In addition to most recommendation-setting bodies that only provide recommendations to maintain vitamin D status, the NutriProfiel recommendations also contain a strategy to diagnose and treat deficiency. It can be expected that doses advised by the Netherlands Health Council $(10$ or $20 \mu \mathrm{g}$ vitamin $\mathrm{D} / \mathrm{d}$ ) will not correct a severe deficiency, a condition that is often encountered in a clinical setting, especially during winter. In addition, ensuring that all subjects reach the optimum $25(\mathrm{OH}) \mathrm{D}$ levels quickly is likely to improve long-term health outcomes. This is supported by meta-analyses, that have revealed that the anti-fracture efficacy correlated with the acquired circulating $25(\mathrm{OH}) \mathrm{D}$ concentrations after supplementation. In addition, it has been speculated that lack of efficacy of vitamin $\mathrm{D}$ in certain RCT can be explained by the fact that these studies were performed in deficient subjects. Therefore, it is likely that using a loading regimen to treat a vitamin $\mathrm{D}$ deficiency will contribute to the long-term health effects of vitamin D.

6. Summary: NutriProfiel advice for dietary intake, plasma/ serum concentrations, and dosing regimens for vitamin $D$

In view of the findings outlined above, we summarise our recommendations in Table 1. We advise using different levels to define deficiency, sufficiency and optimal concentrations of $25(\mathrm{OH}) \mathrm{D}$ for different age groups. Deficiency means that there is insufficient protection against osteomalacia and fractures. Deficiency levels are obtained from previous recommendations ${ }^{(2,3)}$. An optimal concentration means that there is adequate protection against chronic diseases or conditions with a progressive pathophysiology (for example, fracture risk), and sufficiency includes concentrations between deficiency and optimal $25(\mathrm{OH}) \mathrm{D}$ concentrations. Both are derived from the data outlined above. Upper daily intake levels are derived from IOM recommendations.
For children aged $0-4$ years, $10 \mu \mathrm{g} / \mathrm{d}(400 \mathrm{IU} / \mathrm{d})$ would be sufficient, with an optimal $25(\mathrm{OH}) \mathrm{D}$ concentration of $30-50$ $\mathrm{nmol} / \mathrm{l}$.

For 5-64 years $10-20 \mu \mathrm{g} / \mathrm{d}(400-800 \mathrm{IU} / \mathrm{d})$ with an optimal $25(\mathrm{OH}) \mathrm{D}$ concentration range of $50-75 \mathrm{nmol} / \mathrm{l}$ are recommended.

For $>65$ years a daily intake of $20 \mu \mathrm{g} / \mathrm{d}(800 \mathrm{IU} / \mathrm{d})$ and an optimal $25(\mathrm{OH}) \mathrm{D}$ concentration range of $75-100 \mathrm{nmol} / \mathrm{ml}$ are recommended.

No special recommendations are made for pregnant or lactating women, or individuals with a dark skin type.

A loading regimen according to Van Groningen $e t a l .{ }^{(27)}$ can be followed to treat deficiency in adults $>18$ years old, after which the recommended intake should be enough to maintain serum $25(\mathrm{OH}) \mathrm{D}$ levels. The optimal $25(\mathrm{OH}) \mathrm{D}$ concentration is the target, and loading is required when the $25(\mathrm{OH}) \mathrm{D}$ concentration is below the optimal range. Measurements of 25 $(\mathrm{OH}) \mathrm{D}$ after 3 and 9 months will determine whether reference $25(\mathrm{OH}) \mathrm{D}$ concentrations are reached and if dose adjustment is needed. For children $<18$ years old, deficiency is treated by loading with $1 \mu \mathrm{g} / \mathrm{d}$ for every $1 \mathrm{nmol} / 1$ increase in $25(\mathrm{OH})$ $\mathrm{D}$ that is required to reach the optimal range, after which the maintenance dose is recommended.

Safety should not be an issue with the recommended intakes, and 25(OH)D levels should never exceed $220 \mathrm{nmol} / \mathrm{l}$. Ca should only be supplemented when $\mathrm{Ca}$ intake is below recommended values; dietary counselling is advised in these circumstances. Based on these doses, we do not expect hypercalcaemia to occur. Serum Ca levels should only be measured in the unlikely event when hypercalcaemia is suspected.

\section{Acknowledgements}

The authors kindly acknowledge the participants of the workshop meeting for their contribution to the meeting and/or review of the manuscript: Evelien Backx (Wageningen University, the Netherlands), Hans-Peter Bootsma (Gelderse Vallei Hospital, the Netherlands), Fränzel van Duijnhoven (Wageningen University, the Netherlands), Ellen Dutmer (Gelderse Vallei Hospital, the Netherlands), Geert Feith (Gelderse Vallei Hospital, the Netherlands), Inez Jans (Gelderse Vallei Hospital, the Netherlands), André Janse (Gelderse Vallei Hospital, the Netherlands), Ellen Kampman (Wageningen University, the Netherlands), Wout van OrtenLuiten (Gelderse Vallei Hospital, the Netherlands), Nicole de Roos (Wageningen University, the Netherlands), Elvira Schouten (General Practice Bennekom, the Netherlands), Michael Tieland (Wageningen University, the Netherlands), Emmelyne Vasse (Gelderse Vallei Hospital, the Netherlands) and Ben Witteman (Gelderse Vallei Hospital, the Netherlands).

This research received no specific grant from any funding agency, commercial or not-for-profit sectors.

M. G. J. B. performed the literature review and wrote and revised the manuscript; L. C. P. G. M. d. G. and J. K. G. organised the workshop meeting; all authors reviewed and contributed to the revision of the manuscript; F. J. K. and J. K. G. initiated the NutriProfiel collaboration.

The authors declare no conflict of interest. 


\section{Appendix. Workshop participants}

From the Division of Human Nutrition, Wageningen University (Wageningen, the Netherlands)

Evelien Backx (PhD candidate), Fränzel van Duijnhoven (researcher), Lisette de Groot (professor in Nutrition and Ageing; speaker), Ellen Kampman (professor in Nutrition and Cancer), Nicole de Roos (assistant professor) and Michael Tieland (researcher).

\section{From Gelderse Vallei Hospital (Ede, the Netherlands)}

Hans-Peter Bootsma (hospital pharmacist), Ellen Dutmer (rheumatologist), Geert Feith (nephrologist), Inez Jans (dietitian), Jacqueline Klein Gunnewiek (clinical chemist; speaker), André Janse (geriatrician), Wout van Orten-Luiten (scientist), Emmelyne Vasse (dietitian) and Ben Witteman (gastroenterologist).

\section{From General Practice Bennekom (Bennekom, the Netherlands)}

Elvira Schouten (general practitioner).

\section{References}

1. Brouwer-Brolsma EM, Bischoff-Ferrari HA, Bouillon R, et al. (2013) Vitamin D: do we get enough? A discussion between vitamin D experts in order to make a step towards the harmonisation of dietary reference intakes for vitamin D across Europe. Osteoporos Int 24, 1567-1577.

2. Institute of Medicine (2011) Dietary Reference Intakes for Calcium and Vitamin D. Washington, DC: Institute of Medicine of the National Academies.

3. Health Council of the Netherlands (2012) Evaluation of the Dietary Reference Values for Vitamin D. The Hague, the Netherlands: Health Council of the Netherlands.

4. Scientific Advisory Committee on Nutrition (2007) Update on Vitamin D - Position Statement by the Scientific Advisory Committee on Nutrition. London: Public Health England.

5. Nordic Council of Ministers (2014) Nordic Nutrition Recommendations 2012. Copenhagen, Denmark: Nordic Council of Ministers.

6. Muskiet FAJ, Schuitemaker GE, van der Veer E, et al. (2009) Is het vitamine-D-advies van de Gezondheidsraad toereikend? (Is the guideline for vitamin D of the Dutch Health Council adequate?) Ned Tijdschr Klin Chem Labgeneesk 34, 197-198.

7. Heaney RP \& Holick MF (2011) Why the IOM recommendations for vitamin D are deficient. J Bone Miner Res 26, 455-457.

8. Bischoff-Ferrari H \& Willett WC (2013) Comment on the IOM vitamin D and calcium recommendations. http://www.hsph.harvard. $\mathrm{edu} /$ nutritionsource/vitamin-d-fracture-prevention/

9. Vieth R, Bischoff-Ferrari H, Boucher BJ, et al. (2007) The urgent need to recommend an intake of vitamin $\mathrm{D}$ that is effective. $A m$ J Clin Nutr 85, 649-650.

10. Muskiet FA, van der Veer E, Schuitemaker GE, et al. (2010) Response to: Towards an adequate intake of vitamin D. An advisory report of the Health Council of the Netherlands. Eur J Clin Nutr 64, 655.

11. Ahmed SF, Franey C, McDevitt H, et al. (2011) Recent trends and clinical features of childhood vitamin D deficiency presenting to a children's hospital in Glasgow. Arch Dis Child 96, 694-696.

12. Goldacre M, Hall N \& Yeates DG (2014) Hospitalisation for children with rickets in England: a historical perspective. Lancet 383, 597-598.

13. Boonen S, Lips P, Bouillon R, et al. (2007) Need for additional calcium to reduce the risk of hip fracture with vitamin D supplementation: evidence from a comparative metaanalysis of randomized controlled trials. J Clin Endocrinol Metab 92, 1415-1423.
14. Cranney A, Horsley T, O’Donnell S, et al. (2007) Effectiveness and safety of vitamin D in relation to bone health. Evid Rep Technol Assess (Full Rep) 158, 1-235.

15. Bischoff-Ferrari HA, Willett WC, Orav EJ, et al. (2012) A pooled analysis of vitamin $\mathrm{D}$ dose requirements for fracture prevention. N Engl J Med 367, 40-49.

16. Bischoff-Ferrari HA, Willett WC, Wong JB, et al. (2009) Prevention of nonvertebral fractures with oral vitamin $\mathrm{D}$ and dose dependency: a meta-analysis of randomized controlled trials. Arch Intern Med 169, 551-561.

17. The DIPART Group (2010) Patient level pooled analysis of 68500 patients from seven major vitamin D fracture trials in US and Europe. BMJ 340, b5463.

18. Bischoff-Ferrari HA, Willett WC, Wong JB, et al. (2005) Fracture prevention with vitamin $\mathrm{D}$ supplementation: a meta-analysis of randomized controlled trials. JAMA 293, 2257-2264.

19. Heaney RP (2013) Health is better at serum $25(\mathrm{OH}) \mathrm{D}$ above 30 ng/mL. J Steroid Biochem Mol Biol 136, 224-228.

20. Bischoff-Ferrari HA, Giovannucci E, Willett WC, et al. (2006) Estimation of optimal serum concentrations of 25-hydroxyvitamin $\mathrm{D}$ for multiple health outcomes. Am J Clin Nutr 84, 18-28.

21. Barger-Lux MJ, Heaney RP, Dowell S, et al. (1998) Vitamin D and its major metabolites: serum levels after graded oral dosing in healthy men. Osteoporos Int 8, 222-230.

22. Heaney RP, Davies KM, Chen TC, et al. (2003) Human serum 25-hydroxycholecalciferol response to extended oral dosing with cholecalciferol. Am J Clin Nutr 77, 204-210.

23. Cashman KD, Fitzgerald AP, Kiely M, et al. (2011) A systematic review and meta-regression analysis of the vitamin $\mathrm{D}$ intake-serum 25-hydroxyvitamin D relationship to inform European recommendations. Br J Nutr 106, 1638-1648.

24. Cashman KD, Wallace JM, Horigan G, et al. (2009) Estimation of the dietary requirement for vitamin $\mathrm{D}$ in free-living adults $>=64 \mathrm{y}$ of age. Am J Clin Nutr 89, 1366-1374.

25. Cashman KD, Hill TR, Lucey AJ, et al. (2008) Estimation of the dietary requirement for vitamin $\mathrm{D}$ in healthy adults. Am J Clin Nutr 88, 1535-1542.

26. Dawson-Hughes B, Mithal A, Bonjour JP, et al. (2010) IOF position statement: vitamin D recommendations for older adults. Osteoporos Int 21, 1151-1154.

27. Van Groningen L, Opdenoordt S, Van Sorge A, et al. (2010) Cholecalciferol loading dose guideline for vitamin D-deficient adults. Eur J Endocrinol 162, 805-811.

28. Whiting SJ \& Calvo MS (2010) Correcting poor vitamin D status: do older adults need higher repletion doses of vitamin D3 than younger adults? Mol Nutr Food Res 54, 1077-1084.

29. Drincic A, Fuller E, Heaney RP, et al. (2013) 25-Hydroxyvitamin D response to graded vitamin $\mathrm{D}(3)$ supplementation among obese adults. J Clin Endocrinol Metab 98, 4845-4851.

30. Rolland Y, de Souto BP, Abellan Van KG, et al. (2013) Vitamin D supplementation in older adults: searching for specific guidelines in nursing homes. J Nutr Health Aging 17, 402-412.

31. Hathcock JN, Shao A, Vieth R, et al. (2007) Risk assessment for vitamin D. Am J Clin Nutr 85, 6-18.

32. Vieth R (1999) Vitamin D supplementation, 25-hydroxyvitamin D concentrations, and safety. Am J Clin Nutr 69, 842-856.

33. Schöttker B, Haug U, Schomburg L, et al. (2013) Strong associations of 25-hydroxyvitamin D concentrations with all-cause, cardiovascular, cancer, and respiratory disease mortality in a large cohort study. Am J Clin Nutr 97, 782-793.

34. Garland CF, Kim JJ, Mohr SB, et al. (2014) Meta-analysis of allcause mortality according to serum 25-hydroxyvitamin D. Am J Public Health 104, e43-e50.

35. Bolland MJ, Avenell A, Baron JA, et al. (2010) Effect of calcium supplements on risk of myocardial infarction and cardiovascular events: meta-analysis. BMJ 341, c3691.

36. Health Council of the Netherlands (2009) Towards an Adequate Intake of Vitamins and Minerals. The Hague, the Netherlands: Health Council of the Netherlands. 